\title{
Inscapes: Interiority in Architectural Fiction
}

\author{
Stefanie E. Sobelle
}

The dream of discovering a hidden room in one's house is common, but what would happen in reality if one's domestic interior began proliferating doorways, rooms, and hallways where previously there were none? Mark Z. Danielewski's 2000 novel House of Leaves examines this proposition. The novel centres on the notorious (but missing) documentary by a celebrated photojournalist, Will Navidson, in which Navidson leaves New York City in a vain attempt to rescue a troubled marriage. The bourgeois Navidsons - "Will, Karen, Chad, and Daisy" - move into a peculiar old country house in Virginia, which turns out to be larger on the inside than on the outside, an uncanny and unfortunate source of horror for its inhabitants. Yet the interior/exterior disconnect of the Navidson house also allegorises the Heideggerean difficulty of dwelling after the advent of Modernism. According to Heidegger in "Building, Dwelling, Thinking” (original translation 1951), building has ceased to concretise dwelling as a remaining or staying in place, a troubling development then exacerbated in the second half of the twentieth century, when building seemed to serve instead an incessant human uprooting or mobility, a consequence of late capitalism and globalisation. Along these lines, Heidegger suggests that:

... the real plight of dwelling does not lie merely in a lack of houses. The real plight of dwelling is indeed older than the world wars and their destruction. ... The real dwelling plight lies in this, that mortals ever search anew for the nature of dwelling, that they must ever learn to dwell. (Heidegger 1997: 109)

The plight of habitation then rests in the false assumption that building, constructing more shelter, will resolve this questionability in dwelling.

Danielewski explores this challenge of facing dwelling anew in House of Leaves, a novel remarkable in its condensing of this plight. ${ }^{1}$ While House of Leaves presents a series of characters challenged by their attempts to inhabit constructed spaces, Danielewski conceives of the book object, like the house itself, as another form of building in which we might dwell. Therefore, the book faces a similar dilemma as other forms of shelter. At the turn of the twentieth century, Danielewski presents the book object itself as in danger of extinction with the exponential rise of media technologies, technologies that potentially render the traditional book structure obsolete for readers, who now must learn to dwell anew in narratives presented by digital formats. Both the Navidson house, with its infinitesimally shifting and expanding interior spaces, and House of Leaves, dense with allusions and footnotes that suggest another kind of infinity, preclude habitation or a comfortable residing within - at least in any traditional sense - as the novel's opening epigraph hostilely suggests: "This is not for you." Yet House of Leaves is a provocative case of an author representing an architectural interior as a means for exploring the possibilities of the novel form, and in turn the complexity of dwelling as suggested by Heidegger. This essay argues that as much as House of Leaves articulates an impossible residence, it also affirms potentiality, challenging the reader to inhabit the novel - and by extension, the world - in newly attentive and intentional ways.

In literary studies, the development of the novel can be tracked through a type of literature I have referred to throughout my scholarship as the "architectural novel," for which the thematic instability of domestic space merges with the formal 
2 Woolf often uses such spatial analogies to talk about reading and writing fiction: in Jacob's Room (1922), she uses the objects of an uninhabited room to represent the absence - and profound loss - of a young soldier killed during World War I; in Orlando (1928), the inheritance of a house is in paralle with the protagonist's development as a writer; in A Room of One's Own (1929), most famously, Woolf suggests that a private room and an independent income are the two most important factors for a woman's ability to write; in her rather opaque short story "The Haunted House," reading and narrative are in an interplay of haunting and habitation. Mrs. Dalloway (1925), however concerned it is with the relationship between the collective passing of a single day and the life memory of an individual, also privileges its interior spaces; the two climactic occurrences of the novel, Septimus's suicide and Clarissa's moment in her little room, are each the realisation of a subject's connection to the outside world from the position of the house's interior.

3 For further elaboration on Danielewski's use of criticism in the novel, see Steven Belletto (2009) construction of the novel, a term that certainly applies to House of Leaves. Twentieth-century writers such as Virginia Woolf and Georges Perec found architecture to be a useful medium through which to rethink the novel form and its relationship to modern society. Woolf, as an example, draws a plan for To the Lighthouse (1927) in her journals - a large block $\mathrm{H}$ - that she refers to as "two blocks joined by a corridor” (Hussey 1996: 306). ${ }^{2}$ For La vie mode d'emploi (1978; Life, A User's Manual, 2008), Perec employs a section of a nineteenth-century apartment house across which he plays a game of chess; each flat in which the knight lands corresponds to a particular chapter. Both works tease out the relationships between book and novel, house and home, structure and inhabitant, thus daring readers to explore how and why domestic space is constituted in particular ways.

A valuable approach to understand the architectural novel's treatment of interiority is through the concept of "inscape," a term that has been used historically in several ways: Gerard Manley Hopkins's Romantic, poetic sense of inscape meant the inherent quality of a thing (Higgins 2006), while Roberto Matta's Surrealist, aesthetic term referred to the representation of an artist's mental landscape (Cernushi 2004). For my purposes here, however, the term describes the realm of the interior in opposition to a surrounding exterior - inscape as opposed to landscape. My definition, while evocative of its predecessors, extends the treatment of domestic interiority beyond prevailing readings of the home as a metaphor for the psychological. I argue that instead, an author's efforts to depict inscape aims to capture interiority as experienced on two registers: first, by the characters in the novel and second, by the reader of the book. Like the novel, the home is an imaginative space with limitless possibilities, as opposed to the more rigid structure of the book or house that contains it; the architectural novel is then a novel that treats the rigid book object as a clearly delineated spatial domain whose containing action nevertheless holds an expansive, imaginative novel within.

The Navidson house on Ash Tree Lane analogises narratives in general; House of Leaves, as I have suggested, is a parallel project of $t$ wo structures (book and house) that are both bigger on the inside than on the outside, just as the actions of reading and living are necessarily larger than the objects that enclose them. Its content, or story, parallels and even interacts with its form, or construction; the novel masquerades as an assemblage of texts consisting of multiple narrators, namely a semi-itinerant 25-year-old in Los Angeles, Johnny Truant, who finds and reads a pseudo-scholarly account of the film by a deceased blind bibliophile, Zampanò. The whole collection includes Truant's introduction and one set of footnotes; Zampanò's notes, borrowed from mock and real sources that range from literary journals to popular media; an appendix of the letters from Truant's institutionalised mother; and notes presented by some unnamed "editors" along the way. Danielewski includes not only multiple narrators, characters, plots, settings, and fonts, but also a variety of novelistic genres: the horror novel, the epistolary novel, the angry young man novel, the road trip tale, the adventure, the romance, et. al. A reader of House of Leaves can find within Zampanò's criticism of the film Derridean, Freudian, Marxist, and even Heideggerean analyses, among others. ${ }^{3}$ This inclusion of criticism implicates the collaborative nature of reading - the consulting of secondary materials. However, the included criticism preempts the reader's ability to "leave" this book and enter another. This excess contributes to Danielewski's efforts at representing all states of the novel - all states of the reading process.

Although the architectural novel is not a nation-specific genre, House of Leaves is exemplary of its particular import for United States literature. Navidson and his 
wife have chosen a now outdated structure in which to work on their relationship; their choice of a nineteenth-century domicile reflects a prevalent American nostalgia for an imagined restorative domesticity that does not in fact easily extend to contemporary living. Indeed, twentieth-century United States literature very rarely depicts modernist architecture at all. While the architecture within the novel belongs firmly in the nineteenth century (as does its most prominent narrative genre - the Gothic), the architecture of the novel - a collaged collection of footnotes, interviews, poems, letters, graphic play, and visual images - has its footing firmly in the twentieth. Through this formal experimentation, the "book" - a threatened literary medium and an alternative space in which to explore the questionability of dwelling, in Heidegger's sense - finds renewed importance.

House of Leaves then finds its roots in an earlier, more canonical American text - William Faulkner's Absalom, Absalom! (1936) - which also suggests that the anachronistic nineteenth-century house does not ultimately satisfy the mandate of twentieth-century habitation, or what Beatriz Colomina has argued is the "modern transformation of the house [that] produces a space defined by walls of (moving) images". As Colomina writes, "To be 'inside this space is only to see. To be 'outside' is to be in the image, to be seen.” (Colomina 1996: 7) The anachronistic house is at odds with this visual modern and its public propagation of the private interior as a readily circulated image. In Absalom, four characters narrate over 70 years of local history, and the central house in the novel, Sutpen's Hundred, exists primarily through their gossip and stories. While the narrators all consider Sutpen's Hundred to be a mausoleum too grand for its own good, characters live only in a very few of its rooms, and the novel's most significant events occur at its thresholds rather than its interior. The narration of architectural inscapes in Absalom plays at the border between characters' experiences of these domestic spaces and the storytellers' perceptions of those characters and of themselves. The novel's dense, repetitive structure becomes, analogically, a literary house in which the reader is kept outside certain rooms of knowledge, allowed only into the zones of inherited information that the narrators have to offer. In turn, Absalom's houses are not capable of sheltering their inhabitants but instead tend toward the stuffy, the ominous, the inescapable, and the uninhabitable. While Faulkner's overlapping blocks of story attempt the same experiments artistically - simultaneity, dynamism, multiple perspectives, stream of consciousness - and are concerned with the same issues socially and culturally as those of figures ranging from James Joyce and Gertrude Stein to Pablo Picasso and Marcel Duchamp, he uses these spatial, temporal, and narrative tools of Modernism to depict a vernacular landscape still mired in the pre-modern, in the same way that European Modernist architecture arriving in the United States around the time he was writing did not at first change the ordinary landscape so much as change the way in which it could be understood. That is, the innovations of Modernist houses, even though they do not show up in the plot of Absalom, called for a rethinking/reworking of how one dwells in a house much as the literary avant-garde rethought/reworked how one dwells in a book. Absalom's innovative structure suggests another mode of habitation, a resistance to the implicate limitations of the domestic settings it appropriates, and as such offers the modern reader an escape from the sorry fate of its characters.

Faulkner, through his treatment of inscape, suggests alternatives to the conventional narrative and, like Danielewski, new possibilities for dwelling. Colomina writes of mass media culture, "This new condition in which one knows 'everything about everything' represents a critical transformation of traditional culture.” (1996: 160) Faulkner and Danielewski both explore architectural interiors through 
the arrangement of information - an exploration of what we know and how we know it. As I have suggested, House of Leaves, running to more than 700 pages, is a complex analogue for the wider possibilities of dwelling. Danielewski says of his own project,

Really the only thing challenging about my book is the idea of a book itself ... But books don't have to be so limited ... Multiple stories can lie side by side on the page ... Hell pages can be tilted, turned upside down, even read backwards. I'd love to see that. Someone on the subway spinning a book as they're reading it ... [But] books have had this capability all along ... Hell, go open up the Talmud. Books are remarkable constructions with enormous possibilities ... But somehow the analogue powers of these wonderful bundles of paper have been forgotten ... I'd like to see the book reintroduced for all it really is. (Danielewski 2002)

Danielewski's novel is the result of a 10-year exploration into "the analogue powers of these wonderful bundles of paper," that is, into the forgotten possibilities the book format has to offer, especially as their resurrection impinges on a future for the novel. In so doing, he creates a text that is in many ways a house of leaves - a structure full of leaves (as in pages), a living organism (leaves as foliage), an architectural, combinatorial structure (leaves as hinges or movable sections), an emotional catalogue (love letters in the book are referred to as "leaves of feeling," (2000: 350)), and even something active or agent, conjuring "leaves" as a verb (to cause or allow to remain; to give over to another; to abandon; etc.). House of Leaves enacts a unique relationship between the book (as material object) and the novel (as non-material object). The book, then, is the reliable container, the novel within an excessive uncertainty - the novel within larger and more unruly than the container itself.

Such experimental literature disrupts expected entries into the text, in turn creating a more profound invocation of interiority, one with, perhaps, more potential than our traditional habitats. With House of Leaves, Danielewski pointedly disinvites his reader with the aforementioned epigraph and interrupts subsequent entries by appropriating and then revising the collage form, a form dependent on the materiality of its fragments, such as it was understood and effected by the historical avant-garde. He is then innovative in drawing out the analogue powers of the book by maintaining his commitment to the untapped resources of the material object. Consider the difference between a digital watch and an analogue watch: the former represents the movement of time in flashes, discretely, which cannot capture every state of time's progress. The analogue, its opposite, represents the movement of time spatially, continuously; no state of time goes unrepresented. Danielewski is interested in the conflation of time and space for representation, particularly as it is enacted by the reader's corporeal movement among the pages, for the spatial configuration of the book can be made to represent every state of the novel, or at least attempts to do so. Meanwhile, the content of House of Leaves, like its postmodern predecessors, reflects the problem of the book's relation to the novel and helps us to think about it: the central narrative concerns how a house (as material object) does or can represent a home (as immaterial object), suggesting that a house capable of representing a home in such an analogue fashion - in all its states - is an uncanny, unhomely place, but a total event, located in both time and space, nonetheless. Homes are generally represented digitally by the discrete structure of rooms and hallways, but House of Leaves represents home in an analogue form, thereby showing every state of being at home. 
The more the Navidsons unpack, organise, and settle in, the more previously-nonexistent hallways appear, and then grow, and then grow to unimaginable, unmappable sizes and directions. Any attempt at habitation thus turns into a problem of representation for, as one character puts it, "the house as a trope for the unlimited and the unknowable" (Danielewski 2000: 6). The proliferation of the house in Virginia interrupts habitual activity - the family's attempts at both habitation and habitude. The house refuses to be experienced distractedly and instead absorbs its own inhabitants, who become obsessed with and lost in its spaces. Likewise, the readers of Navidson's house become obsessed with and lost in the spaces of narrative, first Truant and Zampanò (who each descend into a kind of madness) and then the reader of House of Leaves (which, 10 years after its first publication, maintains a cult following and obsessive fan base set on decoding its myriad riddles and allusions).

For Danielewski, the actions of reading and living are necessarily larger than the objects that contain them. Form - what in literature one might consider the container - and content interact with and represent each other to become inextricable. In Chapter IX, Danielewski progressively represents the architecture of the house visually on the page and plays on the relationship between a container and its contents. Here, the actual layout begins to look like a kind of section of a very confused building.
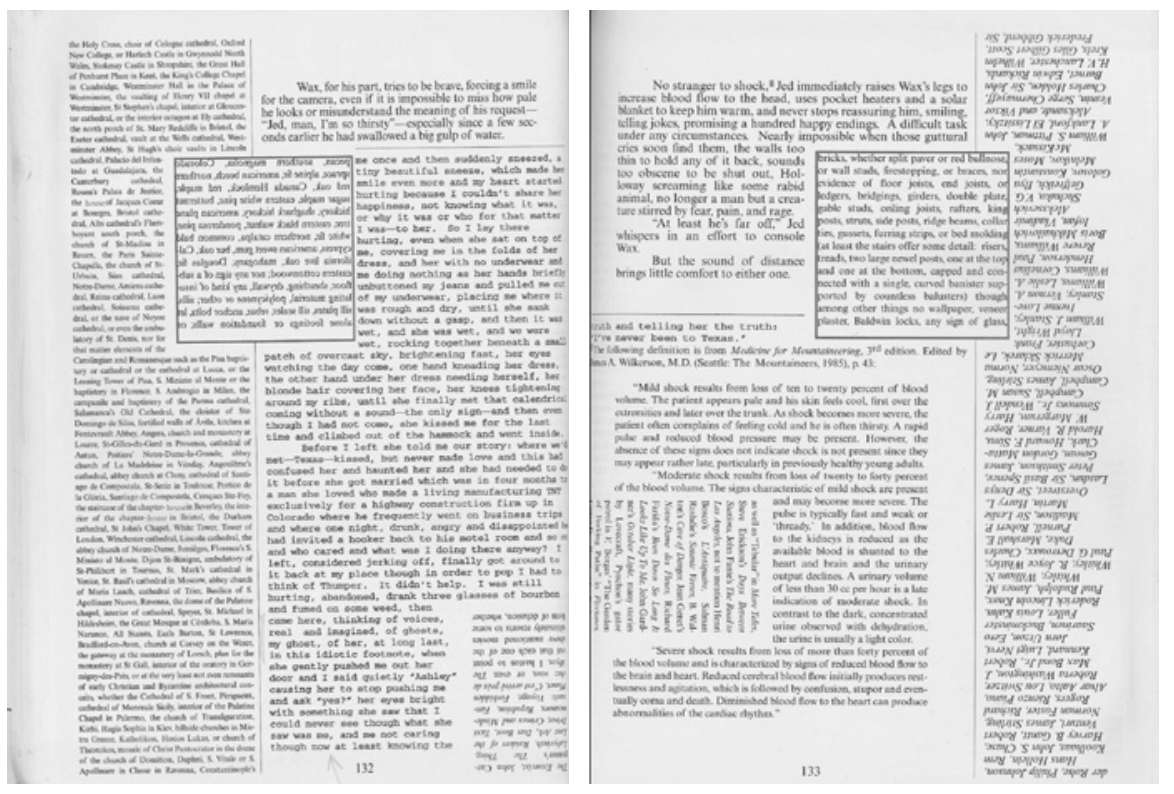

Zampanò begins listing famous architectural sites in one column on the left page, from top to bottom. Inverted and in italics on the far right page, he lists famous architects, in no relation to the building sites from the left. Both columns serve visually as structural support for the centre, as between them are the overlapping stories of Truant's narrative and Zampanò's account of Navidson's, and these are broken up further by other doorways and windows, which in this example consist of an upside down list of films on page 132 and a sideways list of novels on page 133, each in turn cataloguing spaces of horror. The windows themselves are the most explicit example, the text (which lists building tools and materials) reading front to back on the right side and backwards when one turns the page, as though the text is literally written on glass that can be seen from the front and the back. The text continues to offer a variety of openings, passages, stories, and entries, any one
Left: Page 132. From House of Leaves by Mark Z. Danielewski, copyright (C) 2000 by Mark Z. Danielewski. Used by permission of Pantheon Books, a division of Random House, Inc.

Right: Page 133. From House of Leaves by Mark Z. Danielewski, copyright (c) 2000 by Mark Z. Danielewski. Used by permission of Pantheon Books, a division of Random House, Inc. 
Left: "Exterior Photo of Mansion." Winchester, S. (1884-1922). Winchester House. San Jose, CA. Used by permission of the Winchester Mystery House, LLC.

Right: "Staircase to Ceiling." Winchester, S. (1884-1922). Winchester House. San Jose, CA. Used by permission of the Winchester Mystery House, LLC. of which the reader can follow, either singularly or dynamically. Not only are the two narratives intertwined, both characters lost in a labyrinth of pursuing knowledge, but the reader too must follow multiple paths, the act of reading itself progressively personal and internal. House of Leaves demands a corporeal and active engagement with its readers - a literal movement among its passages. Danielewski's assertion of such a bodily relationship with the book - the act of spinning it on the subway, of interacting with it spatially and temporally - is why the book's materiality is so important here: the immediacy and physicality of a book both resists and transcends the passivity and flaccidity that are, as I suggested in the opening, so dangerously a part of contemporary culture.

A built precedent for the literary exploits undertaken in House of Leaves can be found in the Winchester Mystery House (1884-1922), which similarly expresses a proliferating complexity, a restless mobility of form, and a perplexing operational logic. The Winchester House was constructed in the late nineteenth century at a site near San Jose, California. Its owner was the superstitious Sarah Winchester (heir to The Winchester Repeating Arms Company) who, having lost her husband and child prematurely, believed that the victims of the company's guns were now ghosts looking for revenge. The Winchester Repeating Arms Company was famous for inventing the rifle of choice in the "Wild West," and thus the name Winchester implies a nineteenth-century westward expansion that mobilised violence, lawlessness, and a break from the civilised order of the east. ${ }^{4}$ At the advice of a psychic, Winchester believed that unless she built a dwelling configured both to trick and contain the spirits - which meant endlessly rebuilding and modifying it - she herself would fall prey to their vengeance. As a consequence, she moved west and began construction, a process that continued for four decades. As a result, the house became a bizarre maze of corridors leading nowhere, doors opening onto nothing, stairs leading into walls, etc., resembling architectural collage.
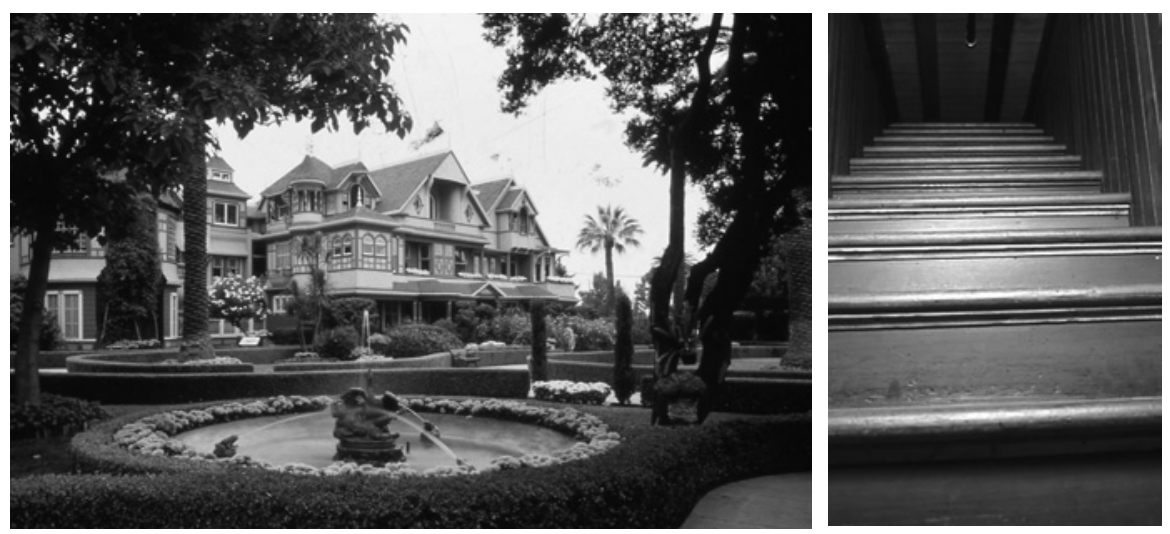

The house, a testament not only to turn-of-the-century superstition and colonial guilt but also to diligence and tenacity, has become a major tourist attraction in northern California.

Far from being a sanctuary from chaos, the Winchester House was nonetheless an act of resistance - a site that was strictly maintained as a bulwark against social upheaval. What Danielewski and Winchester have in common, not only contextually but also formally, is an obsession with passages that almost always fail to perform their function, to close in adequately on a particular destination. Danielewski's house is both claustrophobic and agoraphobic: confining, yet so expansive as to cause terror. Its passages, not its inhabitants, generate more passages; the house turns against its inhabitants. ${ }^{5}$ The Navidson family members are seen and see
4 Mark Hansen (2004) also briefly alludes to Winchester. 
each other, but primarily through video recordings. At the same time that Truant feels paralysed, the family has become increasingly homebound, living and working in an ever more impersonal space.

In his treatment of an interior larger on the inside than on the outside, and in his interest in multiplying passages, Danielewski finds predecessors in something like Stephen Millhauser's 1997 novel Martin Dressler, in which the title character designs a hotel, The Grand Cosmo, that rivals the world, mimicking it in its entirety, past and present. One might think also of Rem Koolhaas's description of the Downtown Athletic Club in Delirious New York (1977), where in the undifferentiated, repetitive scheme of the skyscraper, there exists the possibility for endless variations and superimpositions of an eternal interiority that includes everything, even "eating oysters with boxing gloves, naked, on the 9th floor" according to Koolhaas (quoted in Hays 2000: 327). An even earlier example might be Walter Benjamin's massive Passagen-Werk (1927-1940; The Arcades Project, 2002), a dense collection of passages about passages.

Indeed, Danielewski uses juxtaposed textual passages to think about - write about - architectural passages. Passages, themselves transitory, are spatial and temporal, transporting a subject from one location in one time to another location in another time. Textually, time and space collide, as a reader can revisit different passages slowly, quickly, backward, etc., particularly in a non-linear, collaged work. The interaction of passages on the page allows the events in The Navidson Record to occur simultaneously with Johnny Truant's narrative and even with his analyses of Zampanò's footnotes. As Zampanò intrudes not only on the passage of the body text with a footnote, he has interrupted the reader's journey through that passage by providing interpretation himself, both closing doors to one route and opening passageways to others. Truant, reading this shifting or interruption of passages, responds to this textual moment with sickness, as he, our fictional interpreter, like the reading process, has been violated:

. . . this morning, when I went into work, I didn't feel at all myself. It's probably just a coincidence-I mean that there's some kind of connection between my state of mind and The Navidson Record or even a few sentences penned by a former Nazi . . I've no fucking clue. . . . I walk out into the hallway. That's a big mistake. I should of stayed near people. . . . Instead I'm alone ... then my nostrils flare with the scent of something bitter \& foul, something inhuman, reeking with so much rot and \& years, telling me in the language of nausea that I'm not alone.

Something's behind me.

Of course, I deny it.

It's impossible to deny.

I wanna puke.

To get a better idea try this: focus on these words, and whatever you do don't let your eyes wander past the perimeter of this page. Now imagine just beyond your peripheral vision, maybe behind you ... something is quietly closing in on you, so quiet in fact you can only hear it as silence.

Johnny has been reading an extended passage from Heidegger's Being and Time (1927) excerpted by Zampanò; he in turn offers an English translation in his footnotes, an act then followed by the above episode. Here, reading - a private and thus vulnerable act, usually temporal - becomes a spatial violation. One is trapped

5 The house literally consumes Navidson's twin brother Tom, and in another instance, attacks claustrophobic Karen Green: "Karen avoids the threat in her bedroom only to find herself in a space rapidly enlarging, the size swallowing up all light... The darkness almost immediately crushes Karen. She collapses." (Danielewski 2000: 341) 
in and by text, unable to read without the spectre of criticism, previous and forthcoming, "quietly closing in". Entering passages - literary and fictional - becomes progressively shadowy, anxiety producing. Passages only purport to take the reader through the narrative but instead lead further and further away from a singular clear exegesis.

The very process of interpretation, for Johnny as well as for the reader, is replicated in the maze of passages within the book: textual (citations, overlapping commentaries), visual (page layout), fictional (the house itself proliferates the further into the book one goes), and physical (the reader's spinning, browsing, turning of the book to read it). Danielewski does more here than merely disrupt the temporal linearity of a novel; he takes up the three-dimensional space of architecture and attempts to translate that to literature, including not only its spatial qualities, but also an analogue movement through its passageways. In so doing, Danielewski causes the usual space-time continuum of passages to break down, as they fail to perform their linear transitional function, instead breeding a swarm of movement possibilities.

These movement possibilities, as it turns out, are infinite. The novel offers the following quotation by Dagobert Frey:

Every home is an architecturally structured "path": the specific possibilities of movement and the drives toward movement as one proceeds from the entrance through the sequence of spatial entities have been pre-determined by the architectural structuring of that space and one experiences the space accordingly. But at the same time, in its relation to the surrounding space, it is a "goal," and we either advance toward this goal or depart from it. (Danielewski 2000: 153)

Frey emphasises the simultaneous time-space experience of moving through a passage and the personal, intentional quality of that experience. If every home is an architecturally structured path, every architecturally structured path is a kind of home, including the novel itself. Cognitive scientist Douglas R. Hofstadter, another voice in the novel, describes the design or layout of the house as a version of Zeno's Paradox:

Oh it's very simple. If the arrow is here at A and the target is here at B, then in the course of getting to $\mathrm{B}$ the arrow must travel at least half that distance which I'll call point $C$. Now in getting from $C$ to $B$ the arrow must travel half that distance, call that point $\mathrm{D}$. . . you realize that you can keep dividing up space forever ... until ... well, the arrow never reaches B. (Danielewski 2000: 356)

Under this logic, the house in all its renditions pursues a goal but never reaches it and is thus infinite in potential. House of Leaves, a multitude of architecturally structured passages always emphasises the process of reaching that goal. Yet such infinity also produces a profound anxiety, an anxiety that is the ultimate pathos of the American novel at the end of the twentieth century.

The only solution to that anxiety, Danielewski seems to argue, is to behave like Benjamin's angel of history surveying the ruins that lead to the present, to uncover the possibilities that have been thus far passed over, in order to develop the material conditions antecedent to a given institution (home and novel). As Truant takes 
to the road in search of the house that has been haunting him, he interrogates the history of its location (Virginia) and the very founding of the nation; he finds "no Ash Tree Lane" (Danielewski, 2000: 499), only the Jamestown Colony and Colonial Williamsburg of early America (Danielewski, 2000: 500-2). The anxiety produced by the text comes from the tensions between privacy and public events, between attempting interpretation and the weight of literary and critical history, between expansion and solipsism, safety and violence, passages and stories. The architectural novel offers more than a metaphorical relationship between building and book; rather, it recognises that books are buildings and, as such, enact conditions of living at the end of the twentieth century. The architectural novel allows for the question of dwelling to become dwelling itself, rather than its certitude or its banal repetition. House of Leaves embraces, exemplifies, and demonstrates these concepts through its excess, its hyperness, its exorbitance, suggesting that literary inscapes, and their infinite possibilities, will rescue the novel - and perhaps civilisation as well - from potential extinction.

\section{References}

Belletto, S. (2009). Rescuing Interpretation with Mark Danielewski: The Genre of Scholarship in House of Leaves. Genre (99-117), Fall/Winter 42, 3-4.

Benjamin, W. (2002). The Arcades Project (H. Eiland \& K. McLaughlin, Trans.). Cambridge (Mass.): Belknap Press.

Cernushi, C. (2004). Mindscapes and Mind Games: Visualizing Thought in the Work of Matta and His Abstract Expressionist Contemporaries. In E. Goizuet (Ed.), Matta: Making the Invisible Visible (48-80). Boston (Mass.): McMullen Museum of Art, Boston College.

Colomina, B. (1996). Privacy and Publicity. Cambridge (Mass.): MIT Press.

Danielewski, M. Z. "A Conversation With Mark Danielewski.” Conducted by Sophie Cottrell. April 28, 2002. Retrieved July 9, 2006, from http://www.randomhouse.com/boldtype/0400/ danielewski/interview.html

Danielewski, M. Z. (2000). House of Leaves. New York: Pantheon.

Faulkner, W. (1990). Absalom, Absalom! New York: Vintage Books.

Forham, F. (2011). Katabasis in Danielewski's House of Leaves and two other recent American novels. In J. Bray, J. \& A. Gibbons (Eds.), Mark Z. Danielewski. Manchester: Manchester University Press (33-51).

Hansen, M. (2004). The Digital Topography of Mark Z. Danielewski's House of Leaves. In Contemporary Literature, Volume 45, Number 4 (597-636).

Hays, K.M. (Ed.). (2000). Architectural Theory Since 1968. Cambridge (Mass): MIT Press.

Heidegger, M. (1997). Building, Dwelling, Thinking (A. Hofstadter, Trans.). In N. Leach (Ed.), Rethinking Architecture: A Reader in Cultural Theory (100-109). London: Routledge.

Higgins, L. (Ed.). (2006). The Collected Works of Gerard Manley Hopkins: Volume IV: Oxford Essays and Notes 1863-1868. Oxford: Oxford University Press.

Hussey, M. (1996). Virginia Woolf A to Z. Oxford: Oxford University Press.

Koolhaas, R. (1977). Delirious New York: A Retroactive Manifesto for Manhattan. New York: The Monacelli Press.

Millhauser, S. (1997). Martin Dressler: The Tale of an American Dreamer. New York: Vintage Books. Perec, G. (2008). Life, A User's Manual (D. Bellos, Trans.). Boston (Mass.): David R. Godine.

Woolf, V. (2002). "A Haunted House.” In A Haunted House and Other Stories (3-5). London: Harcourt, Inc.

Woolf, V. (2002). Mrs. Dalloway. London: Harcourt, Inc.

Woolf, V. (1989). A Room of One's Own. London: Harcourt, Inc.

Woolf, V. (1973). Orlando: A Biography. London: Harcourt, Inc.

Woolf, V. (1989). To the Lighthouse. London: Harcourt, Inc. 